\title{
SISTEM PENDUKUNG KEPUTUSAN PEMILIHAN LIPSTIK DENGAN ANALYTICAL HIERRACY PROCESS
}

\author{
Awaliah Nur Ajny \\ PT. Pratama Abadi Industri \\ Jalan Raya Sukabumi - Cianjur KM. 13-14 Blok Satong Parigi, Desa Titisan, Sukabumi \\ e-mail: awaliahnurajny@gmail.com \\ * Korespondensi: e-mail: awaliahnurajny@gmail.com
}

\begin{abstract}
ABSTRAK
Tren dan perkembangan lipstik dikalangan wanita indonesia selalu terjadi dan tidak pernah tenggelam dari masa kemasa. Banyaknya produk lipstik sering kali membingungkan bagi orang yang memiliki sedikit pengetahuan tentang lipstik namun ingin memakainya. Sistem Pendukung Keputusan dengan menggunakan Analytical Hierarchy Process (AHP) merupakan suatu metode pengambil keputusan terhadap masalah penentuan prioritas dari berbagai alternatife. Penerapan AHP dalam penelitian ini adalah menentukan merk lipstik yang sesuai dengan kriteria yang diinginkan. AHP akan mempermudah dan menyederhanakan pengambilan keputusan oleh pengguna lipstik. Berdasarkan perhitungan AHP, diperoleh prioritas kriteria yang paling penting dalam penentuan pemilihan merk lipstick dimana Tekstur, harga dan kemasan menjadi prioritas pengguna dalam pemilihan merek lipstik dan nilai matrik tertinggi diperoleh oleh merek Maybellin dengan nilai matrik 0.26393.
\end{abstract}

Kata Kunci: Merek Lipstik, Perempuan, Analytical Hierarcy Process

\section{ABSTRACT}

The trend and development of lipstick among Indonesian women is always happening and never sinks from time to time. The variety of lipstick products is often confusing for people who have little knowledge of lipsticks but want to use them. Decision Support System using Analytical Hierarchy Process (AHP) is a decision making method for determining priority problems from various alternatives. The application of AHP in this study is to determine the lipstick brand that matches the desired criteria. AHP will simplify and simplify decision making by lipstick users. Based on AHP calculations, the most important priority criteria are obtained in determining the selection of lipstick brands where texture, price and packaging are the priority of the user in choosing the lipstick brand and the highest matrix value is obtained by the Mybelin brand with a matrix value of 0.26393.

Keyword: Lipstick Brand, Female, Analytical Hierarcy Process

\section{PENDAHULUAN}

Lipstik adalah sediaan bentuk batang yang dengan bahan dasar minyak dan lilin yang diberi zat warna merah yang larut atau tersuspensi dalam minyak dan diberi parfum secukupnya [1]. Berdasarkan dari riset yang telah dilakukan oleh snapcart di seluruh Indoneisa dengan menganalisa 2.442 struk belanja perempuan milenial dengan rentang usia 25 hingga 34 tahun yang diambil pada Januari hingga Sep- 
tember 2019, lipstik merupakan salah satu produk kosmetik yang paling laku dipasaran, baik itu di lima kota besar di Indonesia (Jakarta, Surabaya, Medan, Bandung, dan Makassar) maupun dikota lainnya.

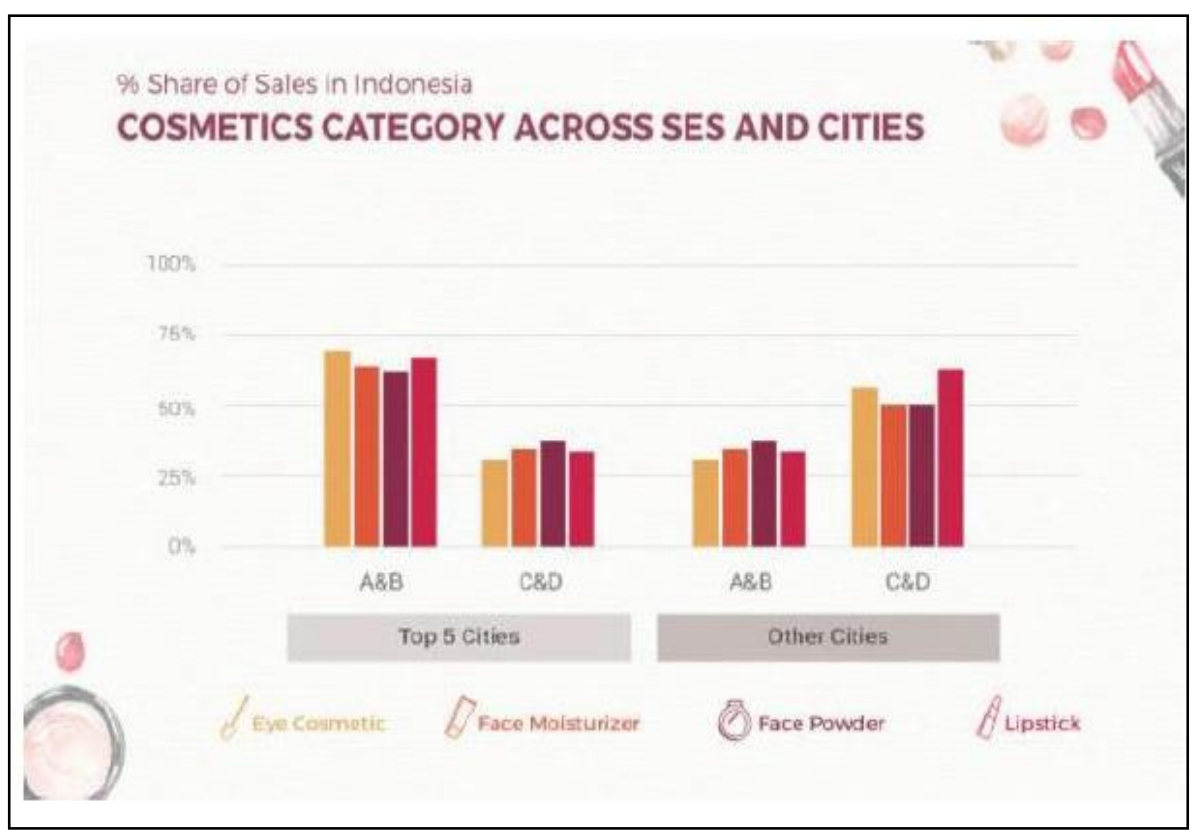

Gambar 1. Grafik Persentase Pembelian kosmetic berdasarkan (Socio Economic Status) [2].

Tren dan perkembangan lipstik dikalangan wanita indonesia selalu terjadi dan tidak pernah tenggelam dari masa kemasa. Begitu banyak produk lipstik yang saling bersaing dipasar baik itu produk lokal maupun luar negri. Banyaknya produk lipstik sering kali membingungkan bagi orang yang memiliki sedikit pengetahuan tentang lipstik namun ingin memakainya. Penulis melakukan penelitian ini dengan menggunakan metode Analytical Hierarchy Process atau AHP, dalam beberapa hal metode AHP cocok dengan masalah yang akan diteliti. Untuk itu penulis membandingkannya dengan beberapa referensi antara metode AHP dengan metode SAW.

Berdasarkan kecocokan perspektif dari 30 orang responden penilaian paket layanan internet hasil yang didapat menggunakan metode AHP menunjukkan 84,62 \% tepat dengan hasil yang diharapkan pengguna, sementara dengan menggunakan metode SAW hanya memperoleh persentase 76,92\% [3]. Jika dibandingkan dengan metode yang lain, AHP memiliki tingkat penilaian yang baik dalam pemilihan dibandingan dengan metode lainnya [4].

Solusi yang diharapkan dalam penelitian ini agar dalam mengambil tingka keputusan jauh lebih konprehensif dibanding dengan metode SAW. Diharapkan penelitian ini dapat memberikan solusi dalam menentukan merek lipstik terbai bagi perempuan yang sesuai dengan kebutuhan serta kriteria pemakainya.

\section{TINJAUAN PUSTAKA}

\subsection{Penelitian Terkait}

Penelitian ini susun berdasarkan referensi penelitian jurnal berdasarkan metode dan permasalahan dalam penelitian. Berikut ini referensi yang digunakan dalam penelitian ini : 
Didit Herdiawan Ashaf Dkk (2019), penelitian tentang sistem pendukung keputusan pemilihan rumah yang berjudul "Decision Support System Determines the Purchase of House Right Using Analytical Hierarchy Proess (AHP) And Borda Methods",. Pada jurnal tersebut menggunakan 4 kriteria lokasi, harga, Fasilitas, alat pencuci. Dan menjelaskan bahwa Sistem pendukung keputusan menggunakan metode AHP dapat memecahkan masalah multi-kriteria dan multi-alternatif, dengan pemungutan prosesn House X dipilih dengan 9 suara, menyimpulkan metode AHP dapat menghasilkan saran pembelian ruah berdasarkan persepsi yang dimasukan oleh calon pembeli rumah [5].

Vadya Maarif Dkk (2019) dengan judul “ Sistem Pendukung Keputusan Pemilihan Skincare yang sesuai dengan jenis kulit wajah menggunakan logika Fuzzy” dengan mentode Fuzzy Logic menggunakan kriteria jenis kulit, Kadar PH (Potential Hydrogen), Kemasan dan Harga. Berdasarkan hasil penelitian dapat disimpulkan bahwa applikasi sistem pendukung keputusan pemilihan skincare dapat mempermudah pengguna dalam memperoleh informasi serta memberikan pengetahuan tentang berbagai jenis produk $f a$ cial foam yang baik untuk digunakan berdasarkan kulit yang dimiliki oleh pengguna [6].

Luthfatul Adhiyah \& Hindayati Mustafidah (2016) dengan judul " Sistem Pendukung Keutusan Pemilihan Lensa Kontak (Softlens) Menggunakan etode Simple Additive Weighting (SAW)" dengan menggunakan kriteria Harga, Masa pemakaian, kandungan air, Warna dan Ukuran Diameter dengan menggunakan Metode SAW dapat disimpulkan bahwa metode simple additive weighting (SAW) merupakan metode yang dapat digunakan dalam pemilihan kontak lensa (softlens) yang menghasilkan alternative terbaik berdasarkan kriteria-kriteria yang telah ditentukan [7].

Husnul Finisa Dkk (2017) yang berjudul "Pemilihan Merek Lipstik Terfavorit dengan berbasis GUI MATLAB”, menggunakan kriteria tekstur, warna, ketahanan, harga, pigmentasi, kemasan dan masa kadaluarsa menggunakan Metode Simple Additive Weighting (SAW). Berdasarkan hasil analisis dan pembahasan diperoleh metode SAW dan TOPSIS dapat digunakan mampu enyelesaikan permasalahan multi atribut dengan banyak pilihan alternative, serta banya pula kriteria yang digunakan untuk melkakukan pemilihan alternative [8].

Hambali Ariff Dkk, yang berjudul "Use of Analytical Hierarchy Process (AHP) for selecting the best design concept" menggunakan kriteria Performance, keamanan, biaya, Ergonomis, Pemeliharaan dengan metode AHP bertujuan untuk memilih desain konseptual kursi roda terbaik, berdasarkan penelitian meyimpulkan bahwa analisis mengungkapkan bahwa konsep desain-5 adalah yang paling tepat untuk pengembangan lebih lanjut karena memiliki yang paling tertinggi nilai $(0,236$ atau $23,6 \%)$ diantara konsep desain lainnya [9].

\subsection{Sistem Informasi}

Menurut Tata Sutardi dalam bukunya "Konsep Sistem Informasi” Sistem Informasi adalah suatu sistem di dalam suatu organisasi yang mempertemukan kebutuhan pengolahan transaksi harian yang mendukung fungsi oprasi organisasi yang bersifat manajerial dengan kegiatan strategi dari suatu organisasi untuk dapat menyediakan kepada pihak luar tertentu dengan laporan-laporan yang diperlakukan.

\subsection{Sistem Pendukung Keputusan}

Sistem Pendukung Keputusan atau SPK adalah sistem berbasis komputer yang iteraktif, yang membantu mengambil keputusan memanfaatkan data dan model untuk menyelesaikan masalah-masalah yang tak terstuktur dan semi terstuktur [10].

\subsection{Merek}

Merek adalah simbol, tanda, rancangan ataupun sebuah kombinasi dari tiga hal tersebut yang ditunjukan sebagai identitas dari beberapa penjual untuk kemudian dijadikan sebagai pembeda dengan pesaing yang ada di pasaran [11].

Perbedaan merek yang satu dengan lainnya diangap sebagai perwakilan simbolis serta emosional yang kedepannya akan berhubungan dengan adanya kinerja sebuah produk yang memiliki merek tersebut. 


\subsection{Lipstik}

Lipstik adalah sediaan bentuk batang yang dengan bahan dasar minyak dan lilin yang diberi zat warna merah yang larut atau tersuspensi dalam minyak dan diberi parfum secukupnya [12].

\subsection{Analitycal Hierarchy Process}

Metode AHP atau Analytical Hierarchy process merupakan salah satu model untuk pengambilan keputusan yang dapat membantu kerangka berfikir manusia. Metode ini mula-mula dikembangkan oleh Thomas L. Saaty seorang ahli matematika yang bekerja pada University of Piitsburgh pada tahun 1970an. Dasar berfikirnya metode AHP adalah proses membentuk skor secara numerik untuk menyusun rangking setiap alternatif keputusan berbasis pada bagaimana sebaiknya alternatif itu dicocokkan dengan kriteria pembuat keputusan. AHP adalah salah satu bentuk model pengambilan keputusan dengan multiple criteria. Metode AHP dapat juga memberikan solusi bagi pihak perusahaan agar mempermudah dalam proses pengambilan keputusan secara tepat dan obyektif [13].

Prinsip pokok AHP dapat dilihat pada gambar 2.

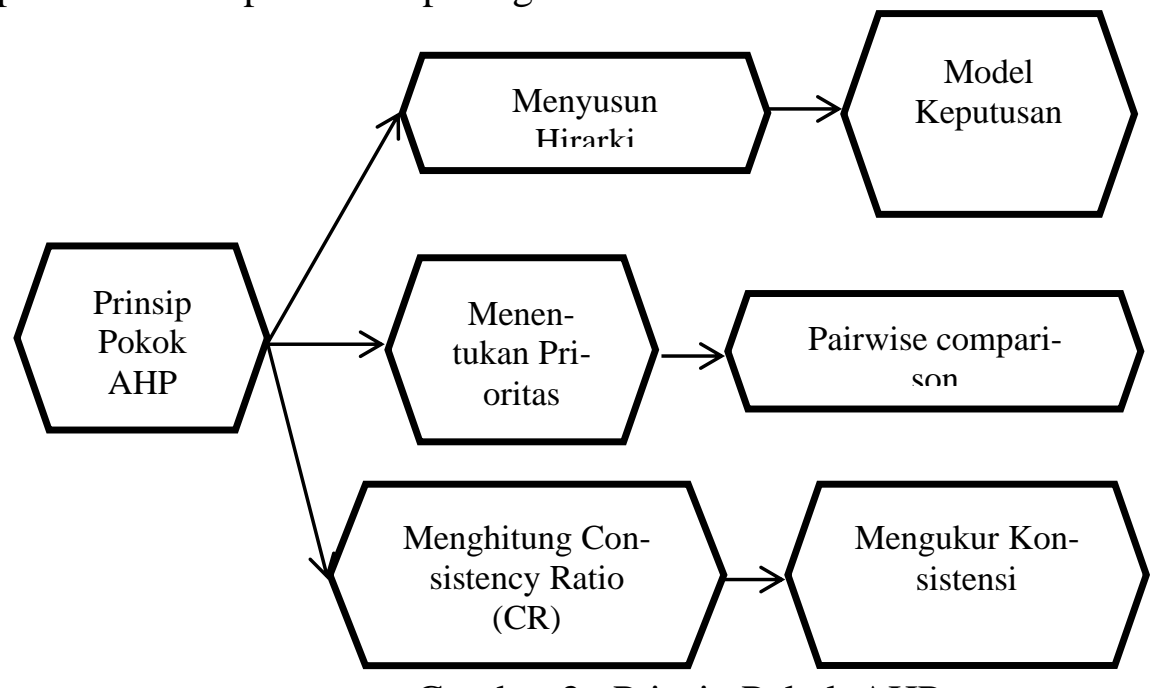

Gambar 2. Prinsip Pokok AHP

Tahapan AHP dapat dilihat pada gambar 3 dibawah.

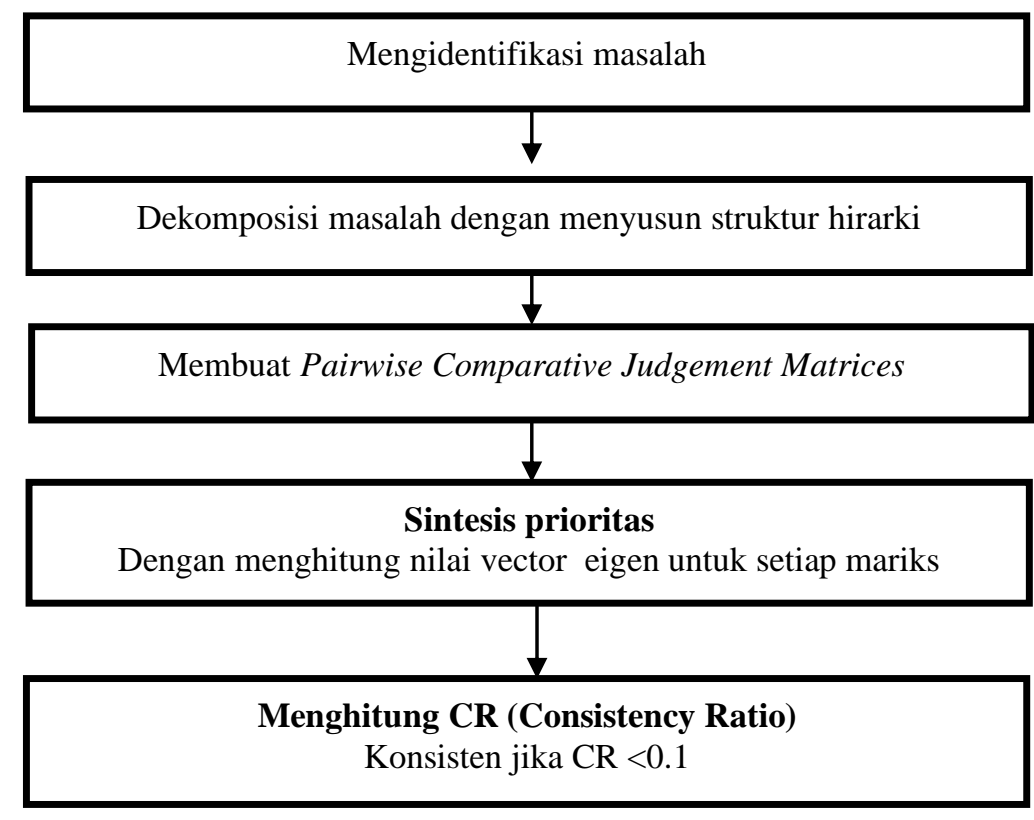

Gambar 3. Tahaan Metode AHP 
Tahapan-tahapan pengambilan keputusan dengan Metode AHP :

1. Mendefinisikan masalah dan menentukan solusi yang diinginkan.

2. Membuat struktur hirarki yang diawali dengan tujuan umum, dilanjutkan dengan kriteria-kriteria, sub kriteria dan alternative- alternatif pilihan yang ingin diurutkan.

3. Membentuk matriks perbandingan berpasangan yang menggambarkan kontribusi relatif atau pengaruh setiap elemen terhadap masing-masing tujuan atau kriteria yang setingkat diatasnya. Perbandingan dilakukan berdasarkan pilihan dari pembuat keputusan dengan menilai tingkat kepentingan suatu elemen dibandingkan elemen lainnya.

\section{METODE PENELITIAN}

Metode yang dilakukan dalam penelitian ini terdiri dari 3 bagian, diantaranya observasi, kuisioner dan studi pustaka.

\subsection{Sampel Penelitian}

Sampel dalam penelitian ini diambil dari daring dengan jumlah sampel yang diambil 50 orang dari dari jumlah populasi 70 orang.

\subsection{Jenis dan Sumber Data}

Data yang digunakan dalam penelitian ini bersumber dari responden, data tersebut diperoleh dari penyebaran kuisioner online, adapun data yang digunakan dalam penelitian iniadalah data kuantitatif. Sumber data dalam penelitian ini diperoleh sebagai berikut:

\section{Data Primer}

Merupakan data-data yang diperoleh langsung dari lapangan oleh peneliti. Data primer diperoleh dari studi lapangan melalui penyebaran daftar pertanyaan/kuisionerr dan wawancara langsung dari narasumber. Informasi yang diperoleh akan diolah untuk menjadi objek analisa terutama dalam menginterpresentaikan atau menjelaskan makna dari data-data yang diperoleh.

Dari hasil observasi didapatkan 5 kriteria yaitu Harga, Aroma, Komposisi, Tekstur dan Kemasan dengan masing - masing kriteria memiliki bobot kriteria, bobot kriteria peneliti dapat di lihat pada tabel di bawah.

Tabel 1. Bobot Kriteria

\begin{tabular}{|l|l|l|}
\hline Kriteria & $\begin{array}{l}\text { Bobot } \\
\text { Kriteria }\end{array}$ & Persentase \\
\hline Harga & 0.30 & $30 \%$ \\
\hline Aroma & 0.04 & $4 \%$ \\
\hline Komposisi & 0.08 & $8 \%$ \\
\hline Tekstur & 0.38 & $38 \%$ \\
\hline Kemasan & 0.20 & $20 \%$ \\
\hline
\end{tabular}

\section{Data Sekunder}

Merupakan data-data tertulis yang bukan diperoleh dari lapangan secara langsung. Data sekunder adalah data yang diperoleh dari studi kepustakaan yaitu pengumpulan data dengan jalan membaca, mempelajari dan menganalisis sumber litelatur yang ada hubungannya dengan objek penleitian, dalam hal ini tentang merek lipstik yang paling dibutuhkan oleh masyarakat Sukabumi. Bentuknya dapat berupa hasil penelitian, artikel ilmiah, terbitan ilmiah seperti jurnal dan sebagainya. 


\subsection{Teknik Pengumpulan Data}

Sumber data yang digunakan diperoleh dari daftar pertanyaan/kuesioner, yaitu pengumpulan data dan informasi terhadap narasumber yang dilakukan dengan lembar wawancara tertulis untuk mendapatkan jawaban atau tanggapan dari responden terkait objek penelitian.

1. Wawancara, merupakan teknik Tanya jawab dengan pihak-pihak terkair penelitian guna menjaring data yang diperoleh dari daftar pertanyaan/kueioner dan data sekunder yang dilakukan dengan mengadakan tanya jawab langsung dengan pihak - pihak yang berkepentingan dalam penelitianm yaitu penguna lipstik dan penjual lipstick

\subsection{Teknik Analisis Data}

Teknik analisis data yang digunakan adalah AHP (Analytical Hierarchy Process), dalam prosesnya AHP memasukan pertimbangan dan nilai-nilai pribadi secara logis yang bergantung pada imajinasi, pengalaman dan pengetahuan. Dilain pihak proses AHP memberikan suatu kerangka bagi partisipasi kelompok dalam pengambilan keputusan atau pemecahan persoalan.

Langkah - langkah penentuan bobot kriteria dan valitas AHP adalah sebagai berikut :

1. Matriks perbandingan berpasangan (pairwaise comparison)

2. Eigen Value

3. Bobot Prioritas

4. Bobot Sintesa

5. Engen Maks (X)

6. $\lambda$ maks (lamda maks)

7. CI (Konsistensi Index)

8. CR (Konsistensi Ratio)

\subsection{Perancangan Sistem}

Perancangan sitem dimaksudkan untuk memberikan gambaran umum kepada pemakai (user) mengenai sistem yang baru. Pada bagian ini akan dijelaskan mengenai alur data dan proses-proses yang terdapat dalam sistem yang akan digambarkan dalam Use Case, Activity Diagram, dan Class Diagram.

1. Use Case

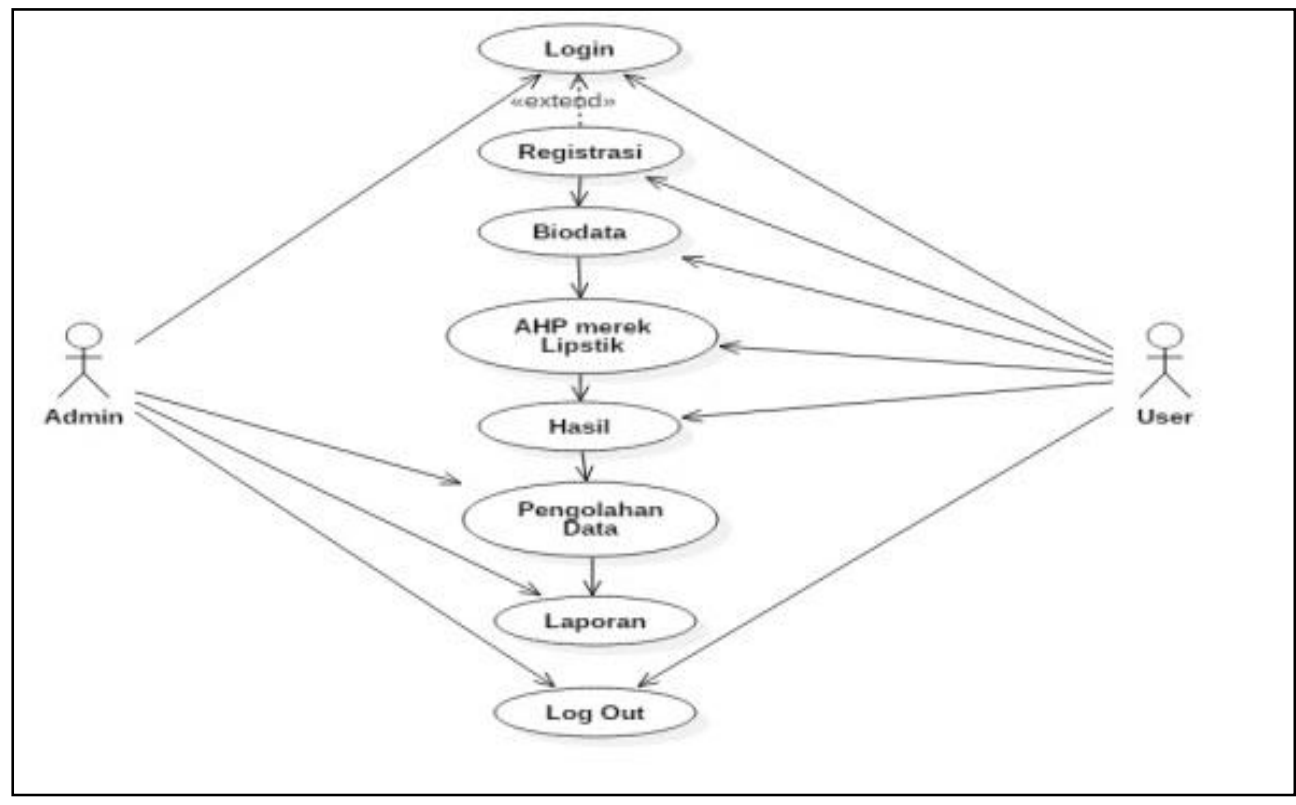

Gambar 4. Usecase Diagram Pendudukung Keputusan Merk Lipstik 


\section{Class Diagram}

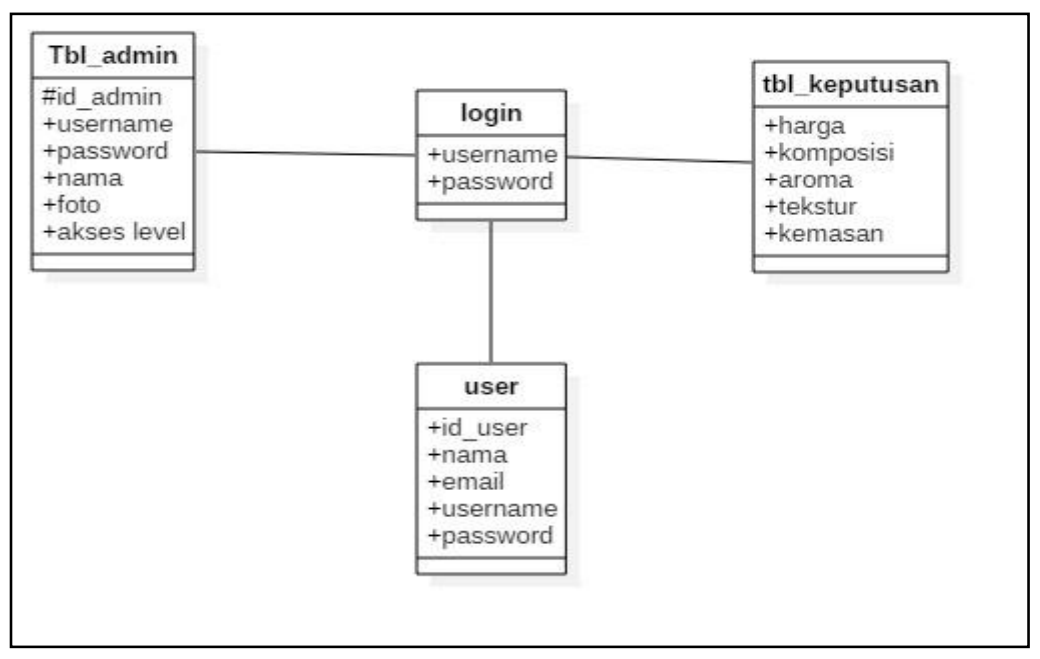

Gambar 3. Class Diagram

\subsection{Implementasi}

Tahap implementasi pada penelitian ini adalah proses pengubahan spesifikasi sistem menjadi sistem yang dapat dijalankan. Implementasi dilakukan dengan menggunakan PHP sebagai bahasa pemograman dengan tujuan membuat dan mengembangkan situs web statis atau situs web dinamis atau applikasi web.

\subsection{Uji Applikasi}

Uji aplikasi menggunakan Uji SQA. SQA atau Software Quality Assurance adalah aktivitas yang digunakan untuk menjamin bahwa proses-proses pengembangan software dilakukan dengan benar, dengan adanya aktivitas SQA ini diharapkan kebutuhan dan target software yang dikembangkan dapat tercapai.

Tabel 2. Metric of Software Quality Assurance (SQA)

\begin{tabular}{|l|l|l|l|}
\hline No & Metrik & Deskripsi & Bobot \\
\hline 1 & Auditability & Memenuhi standard atau tidak & 0.125 \\
\hline 2 & Accuracy & Keakuratan komputasi & 0.125 \\
\hline 3 & Completeness & Kelengkapan & 0.125 \\
\hline 4 & Error Tolernce & Toleransi terhadap kesalahan & \\
\hline 5 & Expandability & Pengembangan perangkat lunak & 0.125 \\
\hline 6 & Operability & Kemudahan untuk dioperasikan & 0.125 \\
\hline 7 & Simplicity & Kemudahan untuk dipahami pembelajaran fasilitas & 0.125 \\
\hline 8 & Training & $\begin{array}{l}\text { Kemudahan } \\
\text { Help }\end{array}$ & 0.125 \\
\hline
\end{tabular}




\section{HASIL DAN PEMBAHASAN}

\subsection{Proses dengan metode AHP}

\section{a. Decomposiont}

Pada tahap ini di buat bentuk hirarki porses pengambilan keputusan, dengan goal merk lipstik menggunakan 5 kriteria dengan mengambil sampel 7 Merk Lipstik. Hirarki pemilihan merk lipstick terbaik dapat dilihat pada gambar 4 .

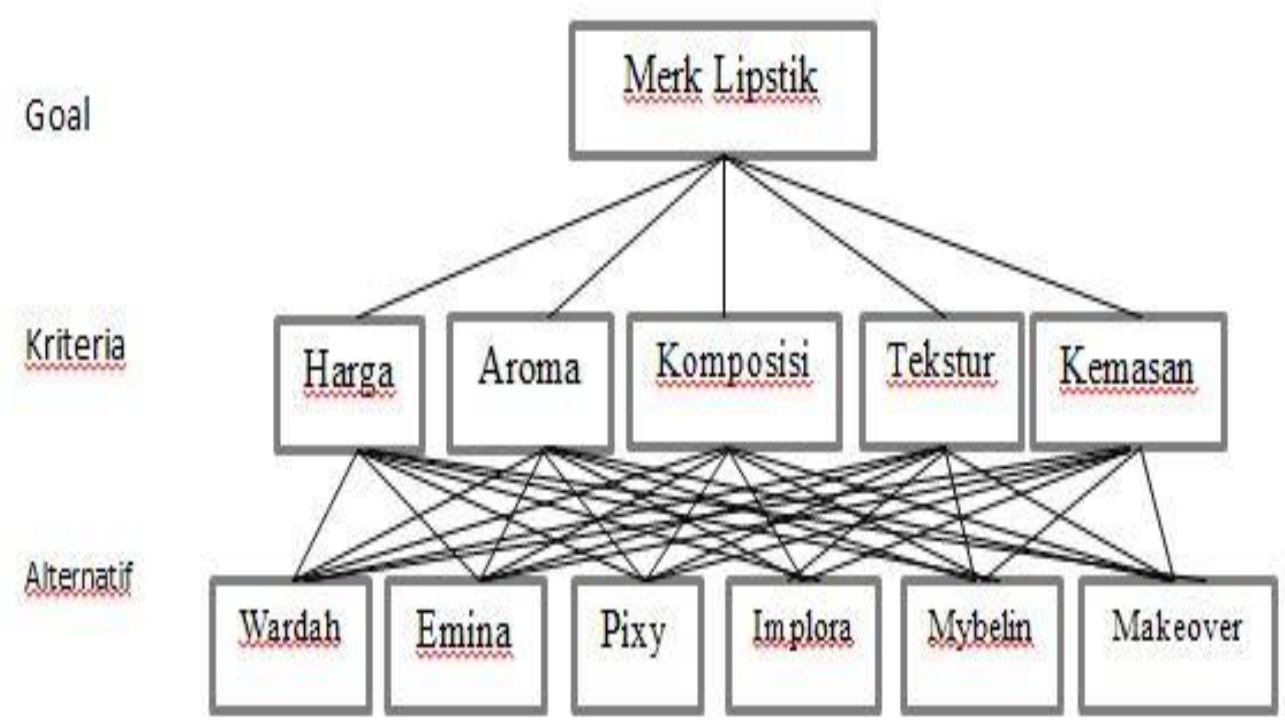

Gambar 4. Hirarki Pemilihan Merk Lipstik

\section{b. Comparative Judgement}

Pada tahap ini dicari nilai perbandingan dengan skala kualitas 1 sampai 9 selanjutnya dicari nilai Eigen Value dan bobot prioritas dengan kolom kriteria eigen value dikali dengan jumlah total eigen value. Matrik perbandingan dapat dilihat pada tabel 3.

Tabel 3. Matrik Perbandingan Berpasangan

\begin{tabular}{|l|r|r|r|r|r|r|r|}
\hline Kriteria & Harga & Aroma & Komposisi & Tekstur & Kemasan & $\begin{array}{c}\text { Eigen } \\
\text { Value }\end{array}$ & $\begin{array}{c}\text { Bobot } \\
\text { Prioritas }\end{array}$ \\
\hline Harga & 1.00 & 5.00 & 5.00 & 4.00 & 0.33 & 2.016 & 0.2627 \\
\hline Aroma & 0.33 & 1.00 & 0.33 & 0.20 & 0.33 & 0.375 & 0.0488 \\
\hline Komposisi & 0.20 & 3.00 & 1.00 & 0.40 & 0.33 & 0.603 & 0.0786 \\
\hline Tekstur & 4.00 & 5.00 & 5.00 & 1.00 & 3.00 & 3.129 & 0.4077 \\
\hline Kemasan & 3.00 & 3.00 & 3.00 & 0.33 & 1.00 & 1.552 & 0.2022 \\
\hline Total & 8.53 & 17.00 & 14.33 & 5.93 & 5.00 & 7.68 & 1.00 \\
\hline
\end{tabular}

\section{c. Synthesis of Priority \& Logical Consistency}

Langkah selanjutnya melakukan normalisasi perbandingan yaitu kriteria/jumlah total dari setiap kolom. Pada tahap ini dibuat matrik perbandingan antar elemen - elemen dan dilakukan sintesa dengan menjumlahkan setiap kolom. Setelah normalisasi nilai perbandingan selanjutnya nialai eigen $\lambda$ tiap kolom dilihat pada tabel 4 . 
Tabel 4. Matrik Normalisasi Perbandingan

\begin{tabular}{|l|r|r|r|r|r|r|r|r|}
\hline & Harga & aroma & $\begin{array}{c}\text { Kom- } \\
\text { posisi }\end{array}$ & tekstur & kemasan & $\begin{array}{c}\text { Bobot } \\
\text { Sintesa }\end{array}$ & $\begin{array}{c}\text { Eigen } \\
\text { Maks } \\
(\mathrm{X})\end{array}$ & $\begin{array}{c}\text { Bobot } \\
\text { Kriteria }\end{array}$ \\
\hline Harga & 0.12 & 0.29 & 0.35 & 0.67 & 0.07 & 1.50 & 5.71 & 0.30 \\
\hline aroma & 0.04 & 0.06 & 0.02 & 0.03 & 0.07 & 0.22 & 4.54 & 0.04 \\
\hline komposisi & 0.02 & 0.18 & 0.07 & 0.07 & 0.07 & 0.40 & 5.14 & 0.08 \\
\hline tekstur & 0.47 & 0.29 & 0.35 & 0.17 & 0.60 & 1.88 & 4.61 & 0.38 \\
\hline kemasan & 0.35 & 0.18 & 0.21 & 0.06 & 0.20 & 0.99 & 4.91 & 0.20 \\
\hline & 1.00 & 1.00 & 1.00 & 1.00 & 1.00 & & 24.91 & 1.00 \\
\hline
\end{tabular}

\subsection{Penentu Merk Lipstik}

Penentu merek lipstik baru menggunakan metode AHP dengan mencari Nilai Matrik Perbandingan setiap kriteria dengan mengambil data calon Pengguna merk lipstick. Setelah Menentukan dan menghitung Matrik Perbandingan setiap kriteria selanjutnya matriks perbandingan di normalisasi dan dicari nilai Bobot Alternatif. Hasil penilaian matrik secara keseluruhan diperlihatkan pada tabel 5 dibawah ini.

Tabel 5. Nilai Matrik

\begin{tabular}{|c|c|c|c|c|c|}
\hline aroma & Komposisi & Tekstur & Kemasan & $\begin{array}{c}\text { Bobot } \\
\text { Prioritas } \\
\text { kriteria }\end{array}$ & $\begin{array}{c}\text { Nilai } \\
\text { Matrik }\end{array}$ \\
\hline 0.19444 & 0.18421 & 0.20253 & 0.20270 & 0.26270 & 0.19224 \\
\hline 0.19444 & 0.19737 & 0.17722 & 0.18919 & 0.04884 & 0.16345 \\
\hline 0.20833 & 0.21053 & 0.20253 & 0.19730 & 0.07861 & 0.20507 \\
\hline 0.19444 & 0.19737 & 0.18987 & 0.19459 & 0.40767 & 0.17530 \\
\hline 0.20833 & 0.21053 & 0.22785 & 0.21622 & 0.20218 & 0.26393 \\
\hline 0.19444 & 0.25000 & 0.22785 & 0.21081 & & 0.22614 \\
\hline
\end{tabular}

Tabel 6. Peringkat Nilai Matrik

\begin{tabular}{|l|l|l|}
\hline Merk & Nilai Matrik & Rangking \\
\hline Wardah & 0.19224 & 4 \\
\hline Emina & 0.16345 & 6 \\
\hline Pixy & 0.20507 & 3 \\
\hline Implora & 0.17530 & 5 \\
\hline Mybelin & 0.26393 & 1 \\
\hline Makeover & 0.22614 & 2 \\
\hline
\end{tabular}

Dari tabel 6 dapat dilihat bahwa nilai tertinggi diperoleh oleh merk Mybelin dengan nilai matrik 0.26393 dibanding dengan merek lainnya. Jika digambarkan dalam bentuk grafik presentase maka dapat dilihat sebagai berikut. 
JURSISTEKNI (Jurnal Sistem Informasi dan Teknologi Informasi) Vol 2, No.3, September 2020: Hal 1- 13 ISSN. P: 2715-1875, E: 2715-1883

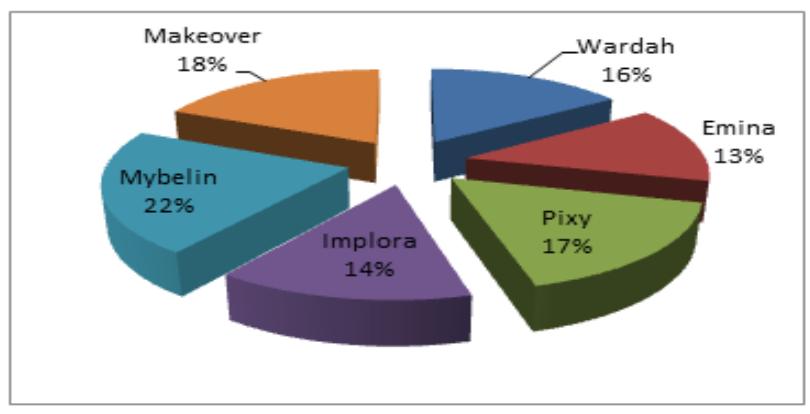

Gambar 5. Grafik Presentasi Nilai Matrik Penentuan Merk Lipstik

\subsection{Implementasi}

Implementasi Pemilihan Bahasa Pemrograman Rancangan Sistem ini dikembangkan dan diimplementasikan dengan bahasa Pemrograman PHP dengan database MySql. Implementasi Rancangan Sistem sebagai berikut :

1. Halaman Login

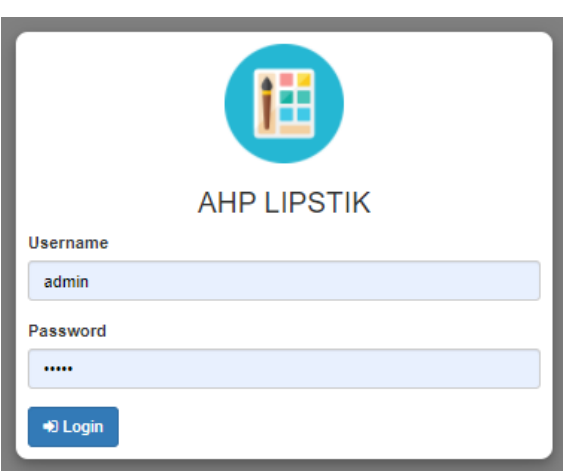

Gambar 6. Halaman Login

2. Halaman Input Kriteria

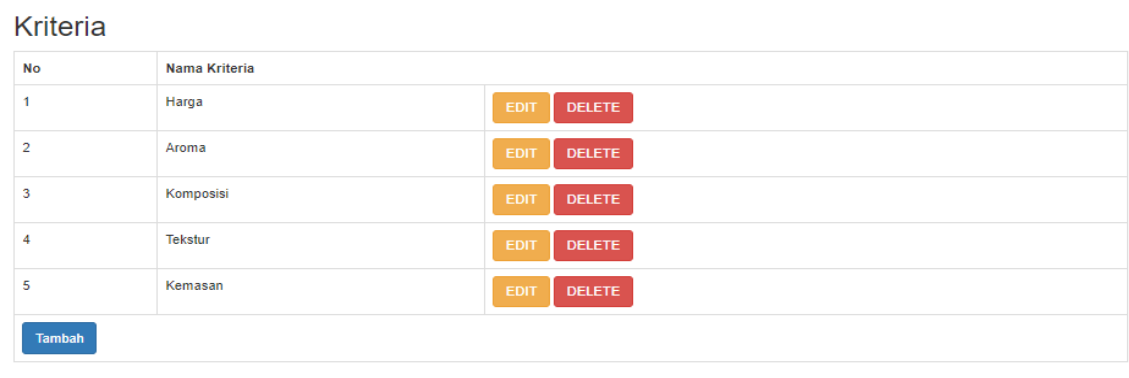

Gambar 7. Halaman Input Kriteri 
JURSISTEKNI (Jurnal Sistem Informasi dan Teknologi Informasi) Vol 2, No.3, September 2020: Hal 1- 13 ISSN. P: 2715-1875, E: 2715-1883

3. Halaman Input Alternatif

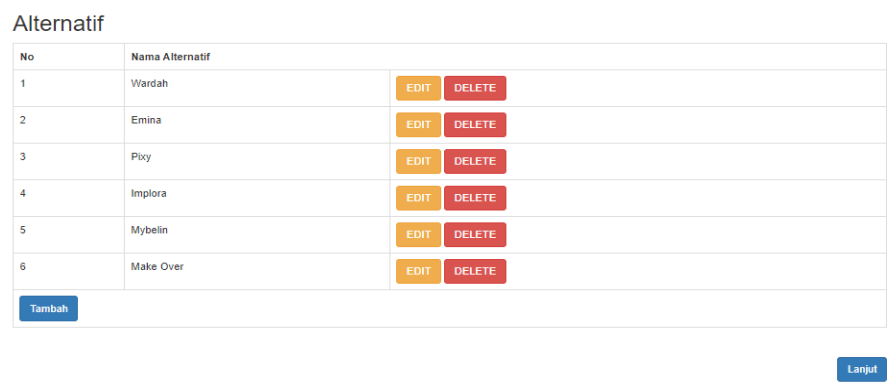

Gambar 8. Halaman Input Alternatif

4. Halaman Perbandingan

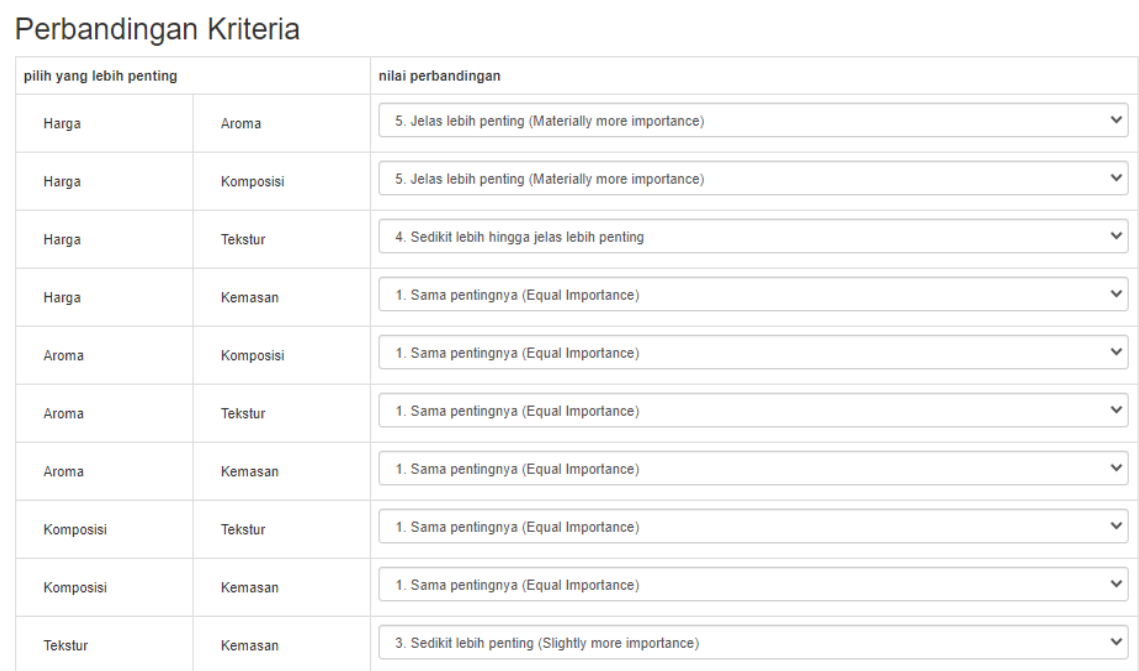

Gambar 9. Halaman Perbandingan

\section{Halaman Matrik Perbandingan}
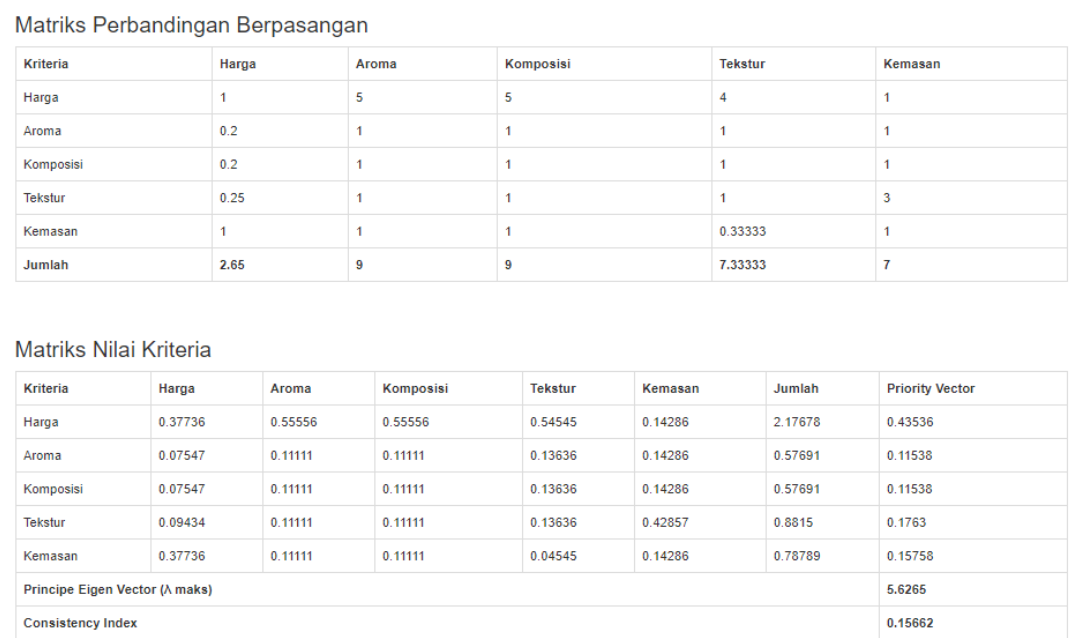

Gambar 10. Halaman Matrik Perbandingan 
6. Halaman Hasil Perhitungan

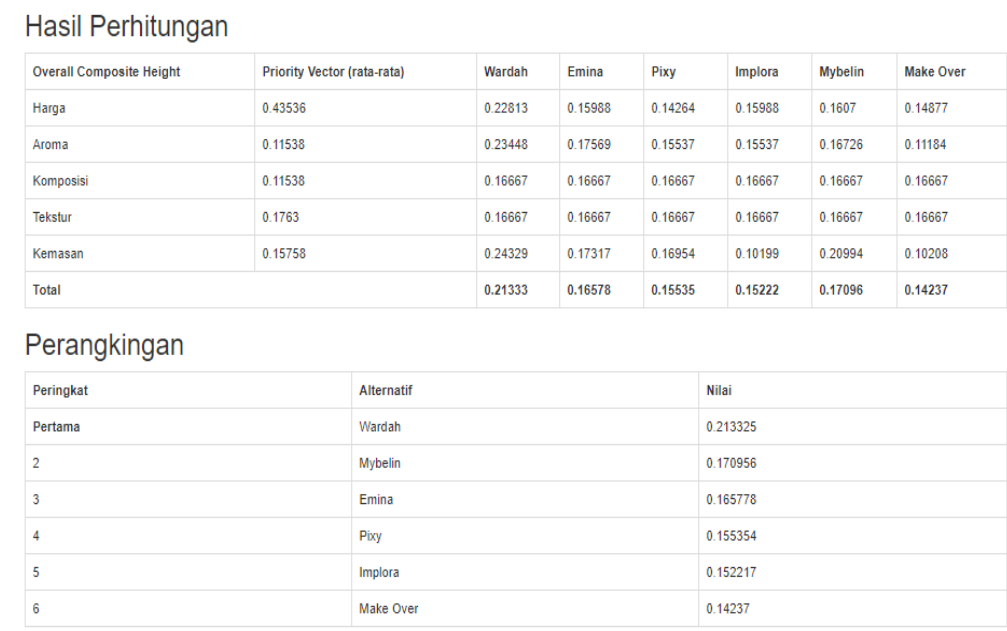

Gambar 11. Halaman Perhitungan

\section{KESIMPULAN}

Berdasarkan tujuan penelitian, pengolahan data dan analisa yang telah dilakukan, maka dapat disimpulkan :

1. Pemilihan merk lipstick dengan menggunakan metode Analytical Hierarchy Process (AHP) dapat membantu pengguna lipstick dalam memilih merk dengan mudah sesuai dengan kriteria yang diinginkan. Jadi dengan dengan adanya metode AHP akan mempermudah dan menyederhanakan pengambilan keputusan oleh pengguna lipstik.

2. Berdasarkan perhitungan AHP, diperoleh prioritas kriteria yang paling penting dalam penentuan pemilihan merk lipstick dimana Tekstur, harga dan kemasan menjadi prioritas pengguna dalam pemilihan merk lipstick dan nilai matrik tertinggi diperoleh oleh merk Mybelin dengan nilai matrik 0.26393 .

3. Sistem Pendukung Keputusan dalam Pemilihan Merk Lipstik dengan metode AHP dibuat dengan pemograman PHP dan MyQL sebagai Database. Dengan pengujian sistem dapat disimpulkan bahwa sistem berjalan sesuai dengan standard an aturan Applikasi. 


\section{DAFTAR PUSTAKA}

[1] Balsam, M.S, Cosmetic Science and Technology edisi kedua. London: John Willy and Son, Inc. Halaman 64, 1972.

[2] Saviq Bachdar, Menganalisis Konsumsi Kosmetik Perempuan Millennials Indonesia. (24 Mei 2017).

[Online], Available: https://marketeers.com/menganalisa-konsumsi-kosmetik-perempuan-milenialindonesia/

[3] Purnomo, et.al, Estining Nur Sujati., Sari Widya Sihwi,. \& Rini Anggrainingsih, Analisis Perbandingan Menggunakan Metode AHP,TOPSIS, dan AHP-TOPSIS dalam studi kasus sistem pendukung keputusan penerimaan siswa program akselerasi. Jurnal Teknologi \& Informasi ITSmart, 2013.

[4] D. Gustian, et.al, "Sistem Keputusan Penilaian KInerja Karyawan dengan Menggunakan Metode Analitical Hierracy Process", Jurnal TAM (Technology Acceptance Model) Volume 9, Nomor 2, Desember 2018.

[5] Ashaf, Didit Herdiawan, Sutijno Wahyu \& Ahmadani, "Decision Support System Determines the Purchase of House Right Using Analytical Hierarchy Proess (AHP) And Borda Methods", International Journal of ASRO Volume 10, number 1,p 1-9, 2019.

[6] Maarif, Vadya,. Et.al, "Sistem Pendukung Keputusan Pemilihan Skincare yang sesuai dengan jenis kulit wajah menggunakan logika Fuzzy”, Jurnal Sains dan Manajemen, 2019.

[7] Adhiyah. Luthfatul \& Hindayati Mustafidah, "Sistem Pendukung Keutusan Pemilihan Lensa Kontak (Softlens) Menggunakan etode Simple Additive Weighting (SAW) ’. JUITA, 2016.

[8] Finisa. Husnul, Tatik Widiharih \& Moch. Abdul Mukid, "Pemilihan Merek Lipstik Terfavorit dengan berbasis GUI MATLAB”, Vol. 6, No.3, 2017.

[9] Ariff, Hambali, et.al, "Use of Analytical Hierarchy Process (AHP) for selecting the best design concept”, Malaysia : Universitas Teknologi Malaysia, 2008.

[10] Turban, Efraim, Jay E Aronson dan Ting Peng Liang, "Decision Support Systems and Intelligent Systems. 7th Edition. New Jersey: PrenticeHall”, 2005.

[11] Kotler, Philip dan Kevine Lane Keller, "Manajemen Pemasaran Edisi 12 Jilid I", Indeks: Jakarta, 2008.

[12] Balsam, M.S., dan Sagarin, E." Cosmetic Science and Technology Volume I". Edisi Kedua. London: John Wiley and Sons. Hal.63-80, 1972.

[13] D. Gustian et.al, "Sistem Pendukung Keputusan Seleksi Penerimaan Karyawan dengan Metode Analytical Hierarchy Process”, Jurnal Komputer Terapan Vol. 5, No. 2, November 2019. 